\title{
Analyses of Transpiration and Growth of Paprika (Capsicum annuum L.) as Affected by Moisture Content of Growing Medium in Rockwool Culture
}

\author{
Nguyen Huy Tai ${ }^{1,2 \dagger}$, Jong Seok Park ${ }^{3 \dagger}$, Jong Hwa Shin ${ }^{1,2}$, Tae In Ahn ${ }^{1,2}$, and Jung Eek Son ${ }^{1,2^{*}}$ \\ ${ }^{1}$ Department of Plant Science, Seoul National University, Seoul 151-921, Korea \\ ${ }^{2}$ Research Institute for Agriculture and Life Sciences, Seoul National University, Seoul 151-921, Korea \\ ${ }^{3}$ Department of Horticultural Science, Chungnam National University, Daejeon 305-764, Korea
}

\begin{abstract}
Since the moisture content (MC) of growing medium closely related with the crop transpiration, the MC should be included to the environmental factors to be considered for irrigation control in soilless culture. The objective of this study was to analyze the transpiration of paprika plants using daily mean solar radiation (RAD) and vapor pressure deficit (VPD) as well as the growth of the plants at different MCs of rockwool growing media. The starting points of irrigation were controlled by a moisture sensor with minimum set points of $40 \%, 50 \%$, and $60 \%$ of MCs. The canopy transpirations were measured for 80 to 120 days after transplanting and analyzed. The transpirations were well regressed with a combination of both RAD and VPD rather than daily mean RAD only under the controlled MCs. The transpiration at $60 \%$ MC was higher than those at $50 \%$ and $40 \%$ MCs. Leaf area, leaf fresh and dry weights at 60\% MC were higher than those at 50\% and 40\% MCs while the number of leaves had no significant difference among the MCs. There were no significant differences in number of fruits and fruit size among all the MCs, while fruit weight was significantly lower at $40 \%$ MC than other treatments. Fresh and dry fruit yields were the highest at 60\% MC. Therefore it was concluded that the transpiration was affected by the MC of rockwool growing medium and the minimum set point of 50-60\% MC of rockwool growing medium gave better effects on the growth of the paprika plants.
\end{abstract}

Additional key words: environmental factor, fruit weight, leaf area, radiation, vapor pressure deficit

\section{Introduction}

Paprika (Capsicum annuum L.) grown under protected cultivation is a valuable crop worldwide, but it is considered as very sensitive to water stress such as an excess or deficit of water. Considering that the growth and yield of plants depend on irrigation and environmental conditions, the paprika plants should be supplied with adequate amount of water to ensure the vigorous growth and fruit yield (Costa and Gianquinto, 2002; Smittle et al., 1994). For this reason, estimation of transpiration which is based on climatic data is essential to satisfy the optimum water requirement and thereby obtain the maximum yield (Harmanto et al., 2005). Transpiration is affected by leaf area and environ- mental factors (Baille et al., 1994a, 1994b; Ta et al., 2011), and solar radiation (RAD) and vapor pressure deficit (VPD) are considered as important factors for establishing irrigation strategy in greenhouse (Jolliet and Bailey, 1992; Medrano et al., 2005; Stanghellini and van Meurs, 1989; Tai et al., 2010; Zhang et al., 2001). For applying adequate irrigation methods, relationships among water and nutrient uptake, transpiration rate, and solar radiation should be analyzed (Adams, 1992; Sonneveld, 2002). At present, one of the methods estimating the evapotranspiration based on timer, pan evaporation, moisture content, or solar radiation is adapted for irrigation in greenhouses. However, selecting only one method for irrigation may not satisfy the water requirement of paprika and sometimes resulted in plant

\footnotetext{
*Corresponding author: sjeenv@snu.ac.kr

${ }^{\dagger}$ These authors contributed equally to this work.

※ Received 6 November 2013; Revised 23 December 2013; Accepted 5 February 2014. This research was supported by iPET (Korea Institute of Planning and Evaluation for Technology of Food, Agriculture, Forestry, and Fisheries).

(C) 2014 Korean Society for Horticultural Science
} 
water stress, low yield and quality, waste water and nutrients. Besides most of the irrigation strategies have particularly concentrated on aerial environment factors. In fact, root-zone environment factor like volumetric moisture content (MC) is important because the moisture content of growing medium is directly related with the transpiration (Park et al., 2009). The objectives of this study were to analyze the canopy transpiration by using solar radiation, VPD, MC of growing medium, and to evaluate the growth, yield, and quality of paprika under the different MCs of rockwool growing media in soilless culture.

\section{Materials and Methods}

\section{Growing Conditions}

This experiment was conducted in a Venlo-type greenhouse at the experimental farm of Seoul National University (Suwon, Korea, Latitude $37.3^{\circ} \mathrm{N}$, Longitude $127.0^{\circ} \mathrm{E}$ ) from the beginning of July to the end of September, 2009. Fifteen days after seeding, paprika (Capsicum annuum L. 'Derby') seedlings were planted on the rockwool cube $(10 \mathrm{~cm} \times 10$ $\mathrm{cm} \times 6.5 \mathrm{~cm}$ ) at the beginning of June, 2009. One month after planting on rockwool cubes, the plants were transplanted in rockwool slabs $(90 \mathrm{~cm} \times 15 \mathrm{~cm} \times 7 \mathrm{~cm})$. The stem density of paprika was $6 \mathrm{stems} / \mathrm{m}^{2}$. The terminal flower of each branch was removed in all the plants to support vegetative growth.

A dripping irrigation system was used for water supply to paprika plants. Drainage was stored in the tank $(20$ L). Growing paprika plants under the different irrigation regimes were controlled with minimum set points of $40 \%$, $50 \%$ and $60 \%(\mathrm{v} / \mathrm{v})$ of MCs in a rockwool slab, using Time Domain Reflectometry (TDR) sensors (WT1000B, Mi-Rae Sensor Co., Ltd., Seoul, Korea) which enable to compensate the values of electrical conductivity (EC) from 20 days after transplanting. MCs in the rockwool slab were controlled with the error of $5 \%$, compared to the target MC. The average inside radiation ranged from 2.6 to $5.5 \mathrm{MJ} \cdot \mathrm{m}^{-2} \cdot \mathrm{d}^{-1}$ and the average inside temperature was controlled at 25 to $30^{\circ} \mathrm{C}$. All the plants were supplied with the nutrient solution of EC 2.5 to $3.0 \mathrm{dS} \cdot \mathrm{m}^{-1}$ and $\mathrm{pH} 5.5$ to 6.5 . EC in rockwool slabs was maintained at 2.5 to $3.5 \mathrm{dS} \cdot \mathrm{m}^{-1}$ during the growth period. To adjust the $\mathrm{pH}, 1 \mathrm{~N}$ nitric acid was used. Additional plant management of pruning and training was carried out every week.

Compositions of the nutrient solution was based on the PBC nutrient solution of Netherlands: $14.17 \mathrm{NO}_{3}{ }^{-}, 1.14$ $\mathrm{H}_{2} \mathrm{PO}_{4}^{-}, 5.92 \mathrm{~K}^{+}, 8.85 \mathrm{Ca}^{2+}, 3.17 \mathrm{Mg}^{2+}$, and $3.2 \mathrm{SO}_{4}{ }^{2-}$ (in $\mathrm{me} \cdot \mathrm{L}^{-1}$ ) as macro elements; and $1.05 \mathrm{Fe}^{2+}, 0.64 \mathrm{Zn}^{2+}, 0.09$
$\mathrm{Cu}^{2+}, 0.57 \mathrm{Mn}^{2+}$, and $0.08 \mathrm{MoO}_{4}{ }^{2-}$ (in $\mathrm{mg} \cdot \mathrm{L}^{-1}$ ) as micro elements.

\section{Environmental Factors and Transpiration Measurement}

Microclimate data, solar radiation and dry and wet bulb temperatures, were measured from the sensors connected to a data logger (CR 1000, Campbell Scientific, Logan, Utah, USA) every $10 \mathrm{~min}$ throughout the growth period. Solar radiation was measured by a pyranometer (SQ-110-L10, Apogee, Logan, Utah, USA) at a height of $2 \mathrm{~m}$ from the ground inside the greenhouse. Dry bulb $\mathrm{T}_{\mathrm{d}}\left({ }^{\circ} \mathrm{C}\right)$ and wet bulb $\mathrm{T}_{\mathrm{w}}\left({ }^{\circ} \mathrm{C}\right)$ air temperatures were measured by psychrometers made with T-type thermocouples. The canopy transpiration was obtained from the slabs weight and the amount of irrigation and drainage by loadcells (model JSB-50, JSB-20 load cell; CAS Co., Ltd., Yangju, Korea). VPD and daily transpiration $\left(\mathrm{TR}_{\mathrm{d}}\right)$ were calculated with $\mathrm{T}_{\mathrm{d}}$ and $\mathrm{T}_{\mathrm{w}}$, and measured weights by the following equations: VPD $=[100$ $\left.-\left(T_{d}-T_{w}\right) / T_{d}\right] / 100 \times 610.7 \times 10^{7.5 T w /(237.3+T w)}$ and $\mathrm{TR}_{d}$ $=$ total irrigation amount - total drainage amount - changed weight of rockwool.

Number of leaves, leaf area, leaf fresh and dry weight were sampled every two or three weeks after transplanting. Leaf areas were estimated from a leaf area model for paprika developed by Tai et al. (2009). Fruit harvest was carried out every two or three times a week for mature fruits which weighted over $100 \mathrm{~g}$ without physiological disorder or disease. Fruit dry weight was obtained after three days at $70^{\circ} \mathrm{C}$ after measuring fresh weight.

\section{Statistical Analysis}

Three irrigation regimes of $40 \%, 50 \%$, and $60 \%$ MCs were designed in randomized complete block with three replications. One replicate included 3 plants grown in a slab. Regression analysis was performed to obtain the relationship between transpiration and RAD only or combinations of RAD and VPD. For comparing the accuracy, the coefficient of determination $\left(R^{2}\right)$ and the root mean square error (RMSE) were used. Treatment means of replications were analyzed and compared using Duncan's Multiple Range Test with significant difference at $p<0.05$. Statistical analysis was conducted using the SAS (SAS Institute, Cary, NC, USA).

\section{Results and Discussion}

\section{Daily Canopy Transpiration under Different MCs}

Cumulative transpiration of paprika plants grown at $60 \%$ MC was higher than at $50 \%$ and $40 \%$ MCs (Fig. 1). In 
the growth period of 80 to 120 days, the transpiration at $60 \% \mathrm{MC}$ was $12.1 \%$ or $29.4 \%$ much more than those at $50 \%$ or $40 \%$ MCs, respectively. It was observed that the canopy transpiration increased with increase of MC during the growth period. Wang et al. (2013) indicated transpiration rate from soil to atmosphere through plant increased with increase of the water potential of soil.

\section{Relationships among Daily Canopy Transpiration, RAD and VPD under Different MCs}

Relationships between daily canopy transpirations and RAD only or combination of RAD and VPD were presented in Table 1. The regression models using RAD and VPD were more accurate with higher $\mathrm{R}^{2}$ and lower RMSE values than those using RAD only at $40 \%, 50 \%$ and $60 \%$ MCs (Table 1). Similar results on relationship analysis between transpiration and RAD based on daily data was reported

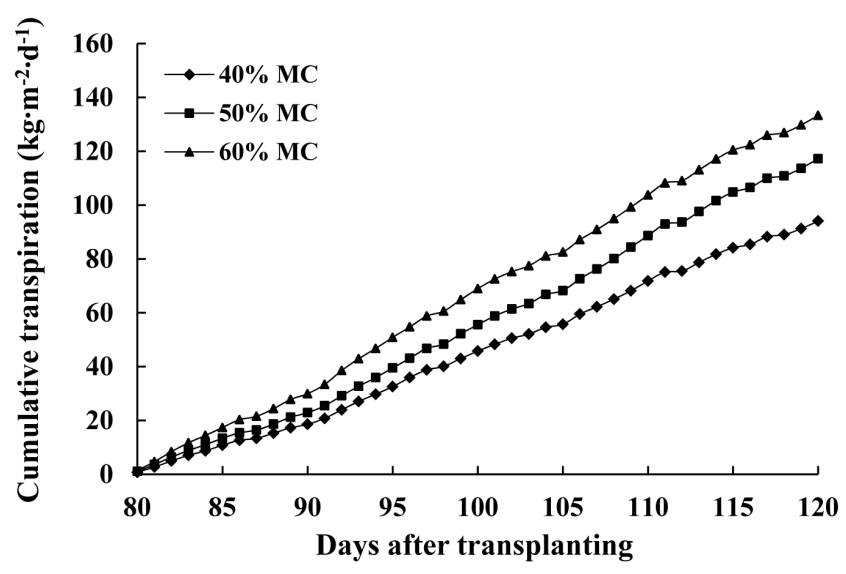

Fig. 1. Cumulative transpiration with days after transplanting of paprika plants grown at $40 \%, 50 \%$, and $60 \%$ moisture contents (MC) of rockwool growing media. for ornamental plants grown in glasshouse (Baas and van Rijssel, 2006; Baille et al., 1994a, 1994b; Stanghellini and van Meurs, 1989).

In this study, canopy transpiration under the controlled MCs was well described by a combined function of RAD and VPD on a daily basis as plane equations. We confirmed that the canopy transpiration had linear relationships with RAD and VPD being affected by the MC of growing medium. In the previous researches, although multiple regression analyses made the models significantly better on the relationship among transpiration, RAD and VPD (Chunpin et al., 2002; Kirnak et al., 2002), the MC was not directly considered for the regression models. Therefore, the models including MC as described in Table 1 can be useful for calculating daily canopy transpiration for paprika plants.

\section{Growth and Yield of Paprika}

No effect of MC in growing medium on number of leaves was observed; however, leaf area was clearly affected by the MC (Fig. 2). This result is similar to the previous results, indicating that leaf area was larger in high MC compared to low MC (Abdel-Mawgoud et al., 2006). At 110 days after planting, the leaf area at $60 \%$ MC was $6.1 \%$ and $11.2 \%$ larger than those at $50 \%$ and $40 \%$ MCs, respectively (Fig. 2B). With almost the same number of leaves for the three controlled MCs, leaf area per plant and average leaf area calculated (data not shown) were larger at $60 \% \mathrm{MC}$, indicating the increase in leaf area size over growth time (Fig. 2B). Hsiao (2000) considered correlating cell and tissue expansion to water stress. Leaf area as a transpiration surface was also smaller under low MC likely because the difference in water use per plant might affect the lower cell expansion rate.

The significant difference in fresh and dry leaf weights

Table 1. Regression models of transpiration $\left(\mathrm{TR}_{1}\right.$ and $\left.\mathrm{TR}_{2}\right)$ of paprika plants associated with daily mean radiation (RAD) only and RAD and vapor pressure deficit (VPD) both at 40\%, 50\%, and 60\% moisture contents (MC) of rockwool growing media, respectively.

\begin{tabular}{llllc}
\hline MC (\%) & \multicolumn{1}{c}{ Regression model } & $\mathrm{R}^{2}$ & $\mathrm{RMSE}^{2}$ & $\mathrm{Pr}>\mathrm{F}$ \\
\hline 40 & $\mathrm{TR}_{1}=0.17+0.09 \mathrm{RAD}$ & 0.815 & 0.375 & $<0.0001$ \\
& $\mathrm{TR}_{2}=-0.24+0.08 \mathrm{RAD}+0.968 \mathrm{VPD}$ & 0.897 & 0.283 & $<0.0001$ \\
50 & $\mathrm{TR}_{1}=0.24+0.12 \mathrm{RAD}$ & 0.853 & 0.403 & $<0.0001$ \\
& $\mathrm{TR}_{2}=-0.20+0.10 \mathrm{RAD}+1.04 \mathrm{VPD}$ & 0.918 & 0.304 & $<0.0001$ \\
60 & $\mathrm{TR}_{1}=0.80+0.11 \mathrm{RAD}$ & 0.715 & 0.570 & $<0.0001$ \\
& $\mathrm{TR}_{2}=0.00+0.07 \mathrm{RAD}+1.90 \mathrm{VPD}$ & 0.927 & 0.291 & $<0.0001$ \\
\hline
\end{tabular}

All variables in the models are significant at $p<0.05$.

${ }^{\mathrm{z}}$ Root mean square error. 

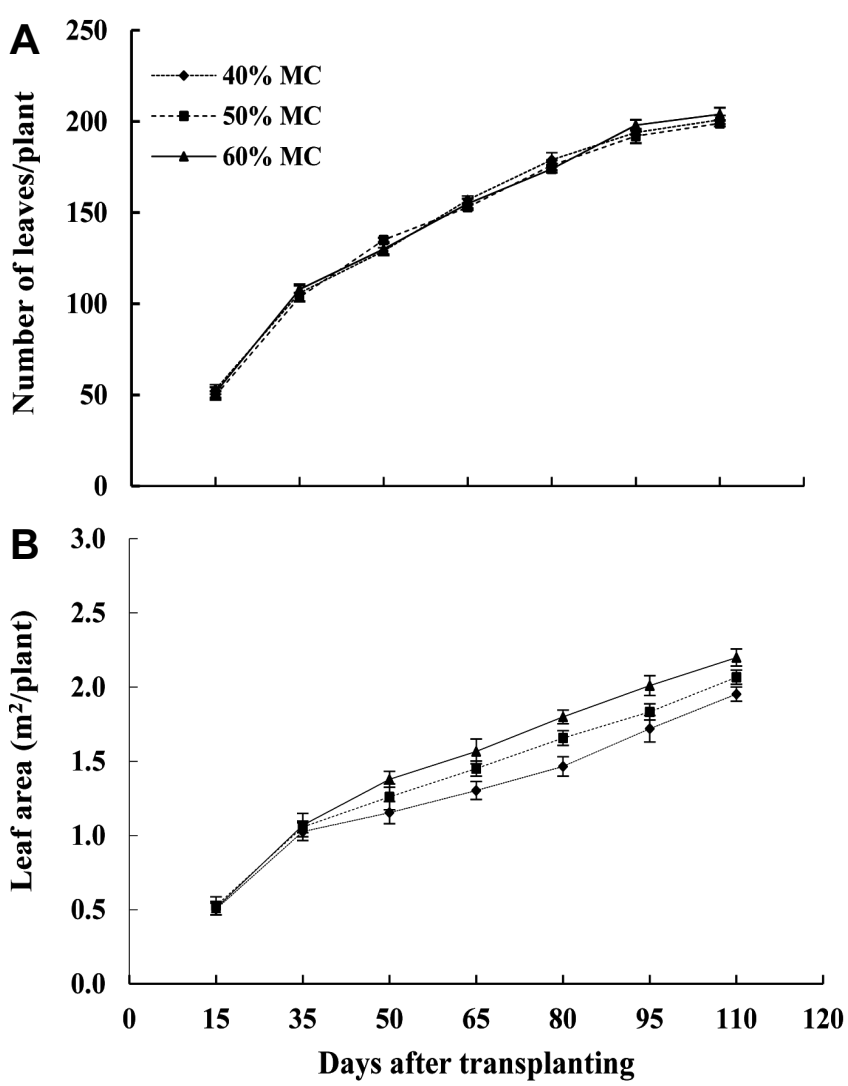

Fig. 2. Number of leaves per plant (A) and leaf area per plant (B) of paprika plants grown at $40 \%, 50 \%$, and $60 \%$ moisture contents (MC) of rockwool growing media. Vertical error bars represent the standard errors $(n=3)$.

of paprika plants grown at different MCs were observed from 35 days to 110 days after transplanting (Fig. 3). Fresh and dry leaf weights were the highest at $60 \% \mathrm{MC}$ and followed by $50 \%$ and $40 \%$ MCs (Figs. 3A and 3B). According to Hsiao (1993), the lower leaf area index under the most deficient water results in less interception of RAD and a continuous decrease in photosynthesis rate and therefore lead to a reduced cumulative biomass and yield. Therefore adequate management of the MC of growing medium is crucial for maintaining enough canopy transpiration and crop growth.

There were no significant differences in number and size of fruits among all the MCs, while fruit weight was significantly lower at $40 \%$ MC (Table 2). Fresh fruit yield per plant at $60 \%$ MC was higher than that at $40 \%$ MC (Fig. 4A). Fresh fruit yield was affected by available MC and optimal leaf area which are necessary for photosynthesis process. The response of the total yield to watering is related with the behavior of the photosynthesizing leaf
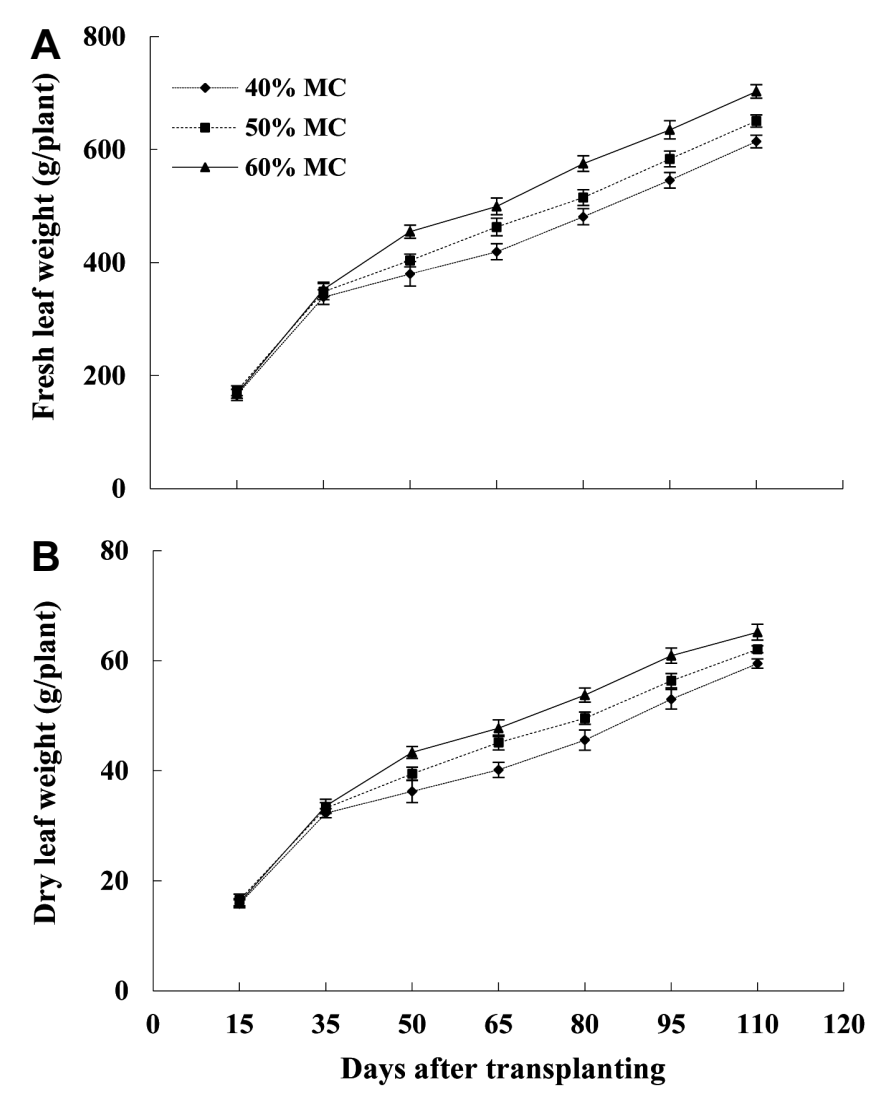

Fig. 3. Fresh (A) and dry (B) leaf weights of paprika plants grown at $40 \%, 50 \%$, and $60 \%$ moisture contents (MC) of rockwool growing media. Vertical error bars represent the standard errors $(n=3)$.

area and biomass accumulation (Hsiao, 2000). Dry fruit yield were a little lower at $40 \% \mathrm{MC}$ than other treatments (Fig. 4A). As an effect of MC, number of fruits (fruit weight $>120 \mathrm{~g}$ ) at $50-60 \%$ MCs was higher than that at $40 \%$ MC (Fig. 4B). For more detail analysis, comparison of marketable rates of paprika at different MCs should be required although it was not conducted in this study.

In this study, simple models were suggested to calculate canopy transpiration using daily base of RAD or a combination of both RAD and VPD for paprika plants under the controlled MCs in rockwool soilless culture. Among the different MCs, $50-60 \%$ MCs in rockwool medium gave better effects on the growth, yield and quality of paprika plants. It was considered that the $\mathrm{MC}$ of growing medium affected the canopy transpiration and growth of paprika plants. As the canopy transpiration could be estimated by using RAD and VPD values under different MCs, these models can be useful for estimation of transpiration and production in soilless culture of paprika plants. 
Table 2. Fruit number, weight, and size (fruit weight $>100 \mathrm{~g}$ ) of paprika plants grown at $40 \%, 50 \%$, and $60 \%$ moisture contents (MC) of rockwool growing media.

\begin{tabular}{lcccc}
\hline MC $(\%)$ & $\begin{array}{c}\text { Number of fruits } \\
\text { /plant }\end{array}$ & $\begin{array}{c}\text { Mean fruit weight } \\
(\mathrm{g})\end{array}$ & $\begin{array}{c}\text { Fruit length } \\
(\mathrm{cm})\end{array}$ & $\begin{array}{c}\text { Fruit width } \\
(\mathrm{cm})\end{array}$ \\
\hline 40 & 10.67 & $147.92 \mathrm{~b}^{\mathrm{z}}$ & 7.99 & 8.03 \\
50 & 11.39 & $159.57 \mathrm{a}$ & 8.22 & 8.15 \\
60 & 11.89 & $160.02 \mathrm{a}$ & 8.41 & 8.35 \\
Significance & NS & $*$ & NS & NS \\
\hline
\end{tabular}

${ }^{\mathrm{z}}$ Mean separation within columns by Duncan's Multiple Range Test at $p<0.05$.

$\mathrm{NS}^{*}$ Nonsignificant or significant at $p<0.05$.
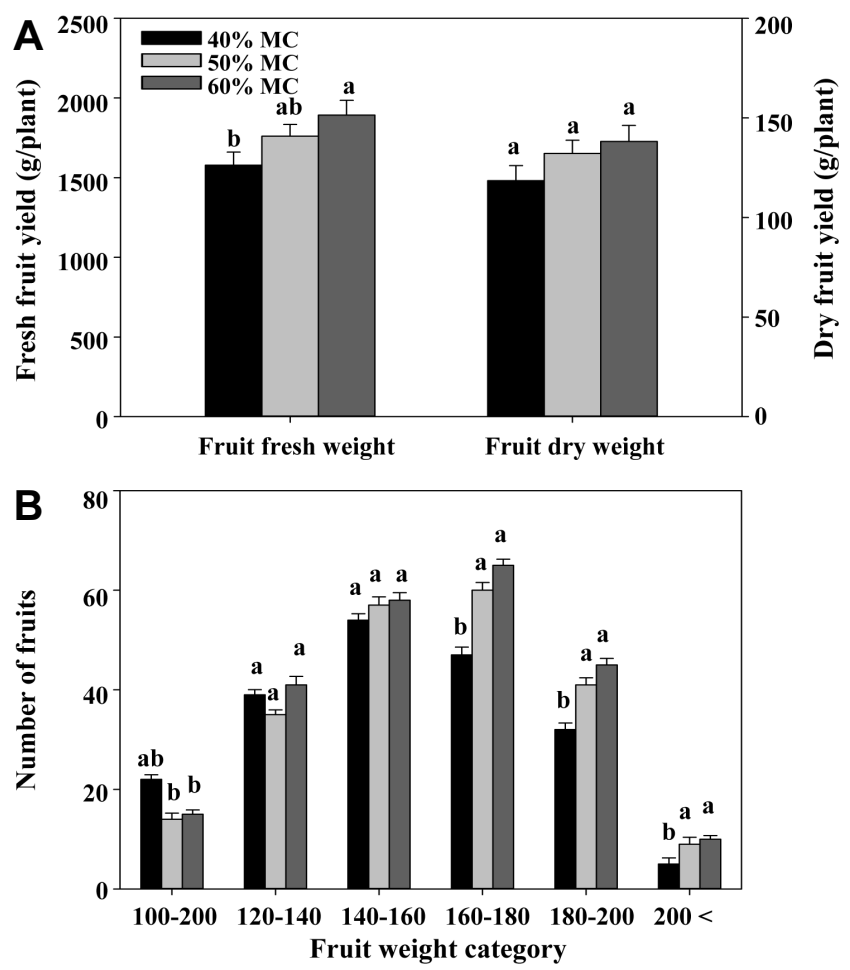

Fig. 4. Fresh and dry fruit weights $(\mathrm{A})$ and number of categorized fruits (> $100 \mathrm{~g}, \mathrm{~B}$ ) of paprika plants grown at 40\%, 50\%, and $60 \%$ moisture contents (MC) of rockwool growing media. Vertical error bars represent the standard errors $(n=3)$. The different letters in the bars are significantly different at $p<0.05$ by Duncan's multiple range test.

\section{Literature Cited}

Abdel-Mawgoud, A.M.R., Y.N. Sassine, Y. Ghora, and E. Heuvlink. 2006. Independent effect of water content in rockwool on water use, growth and production of greenhouse sweet pepper. Euro. J. Sci. Res. 15:235-244.

Adams, P. 1992. Crop nutrition in hydroponics. Acta Hortic. 323: 289-305.
Baas, R. and E. van Rijssel. 2006. Transpiration of glasshouse rose crops: Evaluation of regression models. Acta Hortic. 718:547-556.

Baille, M., A. Baille, and D. Delmon. 1994a. Microclimate and transpiration of greenhouse rose crops. Agr. Forest Meteorol. 71:83-97.

Baille, M., A. Baille, and J.C. Laury. 1994b. A simplified model for predicting evapotranspiration rate of nine ornamental species vs. climate factors and leaf area. Sci. Hortic. 59:217-232.

Chunpin, C., C. Jingcheng, and B. Lin. 2002. Study on simple transpiration model and fitted measurement time for dominant plant at mudstone area in Taiwan. Proc. 12th ISCO Conf. Vol. IV. Index 244.

Costa, L.D. and G. Gianquinto. 2002. Water stress and water table depth influence yield, water use efficiency, and nitrogen recovery in bell pepper: Lysimeter studies. Aust. J. Agric. Res. 53:201-210.

Harmanto, V.M. Salokhe, M.S. Babel, and H.J. Tantau. 2005. Water requirement of drip irrigated tomatoes grown in greenhouse in tropical environment. Agr. Water Manage. 71:225-242.

Hsiao, T.C. 1993. Growth and productivity of crops in relation to water status. Acta Hortic. 335:137-148.

Hsiao, T.C. 2000. Leaf and root growth in relation to water status. HortScience 35:1051-1057.

Jolliet, O. and B.J. Bailey. 1992. The effect of climate on tomato transpiration in greenhouse: Measurements and models comparison. Agr. Forest Meteorol. 58:43-63.

Kirnak, H., T.H. Shorta, and R.C. Hansena. 2002. Studies on the relationships among moisture tension, microclimate and transpiration rate of container grown Acer rubrum. J. Appl. Hortic. 4:65-69.

Medrano, E., P. Lorenzo, M.C.S. Guerrero, and J.I. Montero. 2005. Evaluation and modeling of greenhouse cucumber-crop transpiration under high and low radiation conditions. Sci. Hort. 105:163-175.

Park, J.S., N.H. Tai, T.I. Ahn, and J.E. Son. 2009. Analysis of moisture characteristics in rockwool slabs using time domain reflectometry (TDR) sensors and their applications to paprika cultivation. J. Bio-environ. Control 18:238-243.

Smittle, D.A., W.L. Dickens, and J.R. Stansell. 1994. Irrigation regimes affect yield and water us by bell pepper. J. Amer. Soc. Hort. Sci. 119:936-939.

Sonnenveld, C. 2002. Composition of nutrient solutions, p. 179-210. 
In: D. Savvas and H. Passam (eds.). Hydroponic production of vegetables and ornamentals. Embryo, Athens, Greece.

Stanghellini, C. and W.T.M. van Meurs. 1989. Crop transpiration: A greenhouse climate control parameter. Acta Hort. 245:384-388.

Ta, T.H., J.H. Shin, T.I. Ahn, and J.E. Son. 2011. Modelling of transpiration of paprika plants based on radiation and leaf area index in soilless culture. Hort. Environ. Biotechnol. 52:265-269.

Tai, N.H., J.S. Park, T.I. Ahn, J.H. Lee, D.J. Myoung, Y.Y. Cho, and J.E. Son. 2010. Analysis of relationship among growth, environmental factors and transpiration in soilless culture of paprika plants. Kor. J. Hort. Sci. Technol. 28:59-64.
Tai, N.H., T.H. Ta, T.I. Ahn, J.S. Park, and J.E. Son. 2009. Estimation of leaf area, fresh weight, and dry weight of Paprika (Capsicum annumm L.) using leaf length and width in rockwoolbased soilless culture. Hort. Environ. Biotechnol. 50:422-426.

Wang, X., W. Zhang, and X. Liu. 2013. Daily variation in transpiration and water potential of Robinia pseudoacacia. J. Food, Agr. Environ. 11:999-1005.

Zhang, J.B., Z.P. Yan, Q.R. Li, and Y.J. Ye. 2001. Study on the evapotranspiration model for fitted plant in Taiwan mudstone area. Res. Soil Water Conserv. 8:136-145. 